\title{
Participation of ezrin in bacterial uptake by trophoblast giant cells Kenta Watanabe ${ }^{1}$, Masato Tachibana1, Suk Kim² ${ }^{2}$ and Masahisa Watarai*1
}

\author{
Address: ${ }^{1}$ Department of Veterinary Public Health, Faculty of Agriculture, Yamaguchi University, Yamaguchi 753-8515, Japan and ${ }^{2}$ Department of \\ Veterinary Public Health, Gyeongsang National University, Gyeongnam 660-701, Korea \\ Email: Kenta Watanabe - kentaw@yamaguchi-u.ac.jp; Masato Tachibana - n901tm@yamaguchi-u.ac.jp; Suk Kim - kimsuk@gsnu.ac.kr; \\ Masahisa Watarai* - watarai@yamaguchi-u.ac.jp \\ * Corresponding author
}

\section{Published: 9 September 2009}

Reproductive Biology and Endocrinology 2009, 7:95 doi:10.1186/1477-7827-7-95

This article is available from: http://www.rbej.com/content/7/I/95

Central Ltd.

This is an Open Access article distributed under the terms of the Creative Commons Attribution License (http://creativecommons.org/licenses/by/2.0), which permits unrestricted use, distribution, and reproduction in any medium, provided the original work is properly cited.

\begin{abstract}
Background: Trophoblast giant (TG) cells are involved in systematic removal of bacterial pathogens from the maternal-fetal interface of the placenta. In particular, TG cells have the ability to take up extracellular antigens by active phagocytosis induced by interferon-gamma (IFN-gamma). We previously reported that heat shock cognate protein $70(\mathrm{Hsc70})$ present on the surface of TG cells mediated the uptake of Brucella abortus. However, the mechanism of bacterial uptake by TG cells is not completely understood. Here we identified ezrin, a member of ezrin-radixin-moesin (ERM) protein family, as a molecule associated with $\mathrm{Hsc70.}$
\end{abstract}

Methods: Mouse TG cells were employed in all experiments, and B. abortus was used as the bacterial antigen. Confirmation of the binding capacity of ERM protein was assessed by pull-down assay and ELISA using recombinant $\mathrm{Hsc70}$ and ERM proteins. Ezrin was depleted using siRNA and the depletion examined by immunoblotting or immunofluorescence staining.

Results: The expression level of ezrin was higher in TG cells than in trophoblast stem (TS) cells, and ezrin knockdown TG cells showed a reduction in bacterial uptake ability. Although tyrosine phosphorylation of ezrin was not related to bacterial uptake activity, localization of $\mathrm{Hsc70}$ on the membrane was affected by the depletion of ezrin in TG cells.

Conclusion: Ezrin associates with $\mathrm{Hsc70}$ that locates on the membrane of TG cells and participates in the bacterial uptake by TG cells.

\section{Background}

Trophoblast giant (TG) cells are polyploid cells differentiated from trophoblast stem (TS) cells by many morphological and functional developments; they form the fetal component of placenta [1]. In particular, TG cells play a crucial role in implantation and forming a diffuse network of blood sinuses [2], and promote maternal blood flow to the implantation site in mice [3]. TG cells are essential for establishment of pregnancy. We previously reported that Brucella abortus, an intracellular bacteria that causes abortion in pregnant animals, internalized and replicated in TG cells, specifically in pregnant mice [4]. This study suggested that internalization and replication of Brucella in TG cells play a key role in causing abortion and that TG cells are closely linked to the avoidance of maternal immune rejection. 
Trophoblast cells have a phagocytic ability. During implantation, trophoblast cells invade maternal tissue by phagocytosing the uterine epithelial cells and stroma [5]. Several molecular mechanisms involved in phagocytosis by trophoblast cells have been reported [6], but the complete process remains unclear. It has also been reported that trophoblast cells can phagocytose pathogens and that this activity is enhanced by interferon-gamma (IFN- $\gamma$ treatment) $[7,8]$. Therefore, trophoblast cells may act in a manner similar to that of macrophages in phagocytosis. These studies suggested that trophoblast cells play a role in not only development and maintenance of placenta but also in the defense system of placenta.

Heat shock cognate protein 70 (Hsc70) is a member of the 70-kDa heat shock protein (Hsp70) family. The Hsp70 family is comprised of stress-inducible Hsp70 and constitutively expressed Hsc70. Despite the fact that it shares 80$90 \%$ sequence identity at the amino acid level with Hsp70, Hsc70 has some functional differences compared to the other members of the Hsp70 family. Hsc70 acts as a multifunctional cytoplasmic chaperone protein to fold and assemble newly synthesized proteins, and sort the proteins to different subcellular compartments [9]. In addition, Hsc70 has some characteristic functions such as preventing apoptosis in the neurulating embryo [10], presentation of antigens with MHC class II [11], and chaperone-mediated autophagy [12].

Hsc70 is located in different subcellular compartments; it is found in the nuclear, cytosol, and cellular membrane. Moreover, cytoplasmic Hsc70 shuttles between the nucleus and the cytoplasm $[13,14]$. It has also been suggested that Hsc70 is released from the cells subjected to heat stress or other cytotoxic treatments, although Hsc70 has no secretion leader signal $[15,16]$. Rotavirus reportedly enter host cells using membrane-localized Hsc70 as a receptor [17]. In addition, we have found that Hsc70 is present on the membrane of TG cells, and this is utilized by B.abortus to enter TG cells [18]. It has also been reported that Hsc70 can bind fatty acids and bacterial LPS non-covalently $[19,20]$. These studies support the hypothesis that Hsc70 may participate in the uptake of extracellular antigens by TG cells, and play a principal role in immune function. However, it is unclear how Hsc70 presents on the membrane or acts in TG cells.

Clarification of the function of Hsc70 in TG cells and the phagocytic mechanism of TG cells in pregnant animals requires further investigation. In this study, we identified ezrin, a member of the family of ezrin-radixin-moesin (ERM) proteins, associated with Hsc70 that is located on the TG cell membrane, and investigated the role of ezrin and Hsc70 in bacterial uptake by TG cells.

\section{Methods \\ Cell culture}

TS cells were cultured in TS medium in the presence of FGF4, heparin, and mouse embryonic fibroblast (MEFs)conditioned medium as described previously [18]. The TS medium was prepared by adding $20 \%$ fetal bovine serum (FBS), $1 \mathrm{mM}$ sodium pyruvate, $100 \mu \mathrm{M} \beta$-mercaptoethanol, and $2 \mathrm{mM}$ L-glutamine to RPMI 1640. To induce differentiation to TG cells, the cells were cultured in the TS medium alone for 3 days (about $80 \%$ of cells were differentiated to TG cells) at $37^{\circ} \mathrm{C}$ in a $\mathrm{CO}_{2}$ incubator. J774 cells were cultured in RPMI 1640 containing 10\% fetal FBS.

\section{Bacterial strains}

All B. abortus derivatives were from 544 (ATCC23448) smooth virulent $B$. abortus biovar 1 strains. Ba600 (544 $\mathrm{GFP}+$ ) was used in this study [4]. B. abortus strains were maintained as frozen glycerol stocks and cultured on Brucella broth (Becton Dickinson, Franklin Lakes, New Jersey, USA) or Brucella broth containing 1.5\% agar.

\section{Identification of protein that interacts with $\mathbf{H s c 7 0}$}

TG cells $\left(3 \times 10^{5} / \mathrm{ml}\right)$ were seeded into each well of a 6 well plate. Protein isolations for the cytoskeleton, nucleus, membrane, and cytosol fractions were performed using the ProteoExtract Subcellular Proteome Extraction kit as described by the manufacturer (Calbiochem, Darmstadt, Germany). The membrane fraction proteins of TG cells $(50 \mu \mathrm{g} / \mathrm{ml})$ were separated on $8 \%$ and $12 \%$ polyacrylamide gels and transferred to a polyvinylidene fluoride (PVDF) membrane, which was incubated for $1 \mathrm{~h}$ at room temperature with peroxidase (POD)-conjugated Hsc70 at a dilution of 1:2000 in phosphate-buffered saline (PBS). POD-conjugated Hsc70 was prepared using the Peroxidase Labeling Kit (Dojindo Molecular Technologies Inc., Kumamoto, Japan). The proteins reacting with Hsc70 were extracted and identified by means of nano LC-MS/ MS analysis and MASCOT database searches (APRO life Science Institute, Tokushima, Japan).

\section{Expression and purification of recombinant proteins}

The total RNA of TG cells was isolated using an RNA purification kit (Qiagen, Hilden, Germany). RNA was quantified by absorption at $260 \mathrm{~nm}$ using SmartSpec3000 spectrophotometer (Bio-Rad, Hercules, California, USA). RT-PCR was carried out using a Superscript II kit (Invitrogen, Carlsbad, California, USA). The following primers were used for cloning each gene, ezrin, 5'-GAATTCATGCCCAAGCCAATCAACGTCCGG-3' (EcoRI site underlined) and 5'-GTCGACCT ACATGGCCTC GAACTCGT CAAT-3' (Sall site underlined); radixin, 5'-CTCGAGATGCCGAAGCCAATCAATGTAAGA-3' (XhoI site underlined) and 5'-GTCGAC TCACATGGCTT CAAA CTCATCGAT-3' (SalI site underlined); moesin, 5'-CTC- 
GAGATGCCGAAGACGATCAGTGTGCGT-3' (XhoI site underlined) and 5'-GTCGACCTACATGGACTCAAACTCATCAAT-3' (SalI site underlined); Hsc70 full length, 5'CTCGAGATGTCTAAGGGACCTGCAGTT-3' (XhoI site underlined) and 5'-GTCGACTTAATCCACCTCTTCAATGGT-3' (SalI site underlined); Hsc70 ATP binding domain, 5'-CTCGAGATGTCTAAGGGACCTGCAGTT-3' (XhoI site underlined) and 5'-GTCGACAGACTTGTCTCCAGATAGAAT-3' (SalI site underlined); and Hsc70 peptide-binding domain, 5'-CTCGAGGAGAAC GTTCAGGAT TTGCTG-3' (XhoI site underlined) and 5'-GTCGACTTAATCCACCTCTTCAATGGT-3' (SalI site underlined). These products were cloned into the pCold TF vector (Takara Bio Inc., Shiga, Japan). The His-tagged recombinant proteins were expressed in the Escherichia coli strain DH $5 \alpha$, and purified by Ni-NTA chromatography (Qiagen). The His-tagged proteins were cleaved using human rhinovirus $3 \mathrm{C}$ protease according to the manufacturer's instructions (Novagen, Darmstadt, Germany).

\section{Immunoblotting}

The cell lysates were separated on $10 \%$ polyacrylamide gels and transferred to a PVDF membrane, which was incubated for $1 \mathrm{~h}$ at room temperature with primary antibody, anti-Hsc70 rat monoclonal antibody (mAb) (SPA815; Stressgen, Victoria, BC, Canada) at a dilution of 1:5000 and anti-ezrin, anti-radixin, and anti-moesin rabbit mAb (EP924Y, EP1862Y, and EP1863Y; EPITOMICS, Burlingame, California, USA) at a dilution of 1:2000 in $5 \%$ skim milk. It was then washed three times in Tris-buffered saline (TBS) with $0.02 \%$ Tween 20, incubated for 30 min with an HRP-conjugated secondary antibody at 0.01 $\mu \mathrm{g} / \mathrm{ml}$, and then washed again. Immunoreactions were visualized using the enhanced chemiluminescence detection system (GE Healthcare Life Science, Little Chalfont, $\mathrm{UK})$.

\section{Pull-down assay}

For the pull-down assay, protein $\mathrm{G}$ agarose bead-bound mAbs for each protein $(20 \mu \mathrm{g} / \mathrm{ml})$ were added to $1 \mathrm{ml}$ of purified Hsc70 or each ERM protein mixture $(20 \mu \mathrm{g} / \mathrm{ml})$ in PBS and the mixture was incubated at $37^{\circ} \mathrm{C}$ for $2 \mathrm{~h}$. The precipitates were washed with PBS, analyzed by means of sodium dodecyl sulfate-polyacrylamide gel electrophoresis (SDS-PAGE), and stained with Coomassie Brilliant Blue (Wako, Osaka, Japan).

\section{ELISA}

The ability of ERM proteins to bind Hsc70 was measured as follows. A $100-\mu \mathrm{l}$ aliquot of each ERM protein $(10 \mu \mathrm{g} /$ $\mathrm{ml}$ ) was placed in the wells of 96-well immunoplates (Nalge Nunc, Rochester, NY, USA) and incubated at room temperature for $2 \mathrm{~h}$. The samples were then removed, and the wells were washed twice with PBS-0.05\% Tween 20.
PBS containing 5\% bovine serum albumin (BSA) was added in each well for blocking and incubated at $37^{\circ} \mathrm{C}$ for $30 \mathrm{~min}$. A $100-\mu \mathrm{l}$ aliquot of $\operatorname{Hsc} 70(20 \mu \mathrm{g} / \mathrm{ml})$ was added and the plate was incubated at $37^{\circ} \mathrm{C}$ for $2 \mathrm{~h}$. The amount of bound Hsc70 was determined using ELISA with antiHsc70 rat $\mathrm{mAB}$.

\section{Immunofluorescence microscopy}

TG cells grown on coverslips in 12-well plates were washed twice with PBS, fixed in 4\% paraformaldehyde for $30 \mathrm{~min}$ at room temperature and permeabilized in $0.2 \%$ or $0.01 \%$ Triton X-100. After washing three times with PBS, samples were incubated with primary antibodies: anti-Hsc70 (Stressgen), anti-ezrin (EPITOMICS), and anti-p-Ezrin (Tyr 146 and 354) (Santa Cruz Biotechnology, Inc., Santa Cruz, CA, USA) antibodies at 1:200 dilution, or Alexa Fluor 594-phalloidin (Molecular Probes, Eugene, Oregon, USA) at $20 \mu \mathrm{g} / \mathrm{ml}$ in PBS for $60 \mathrm{~min}$ at $37^{\circ} \mathrm{C}$. After washing three times with PBS, samples were incubated with TRITC or FITC-labeled goat anti-rat or anti-rabbit IgG at $0.01 \mu \mathrm{g} / \mathrm{ml}$ in PBS at $37^{\circ} \mathrm{C}$ for $60 \mathrm{~min}$. Samples were then placed in mounting medium $(90 \%$ glycerol containing $1 \mathrm{mg} / \mathrm{ml}$ phenylenediamene in PBS, pH 9.0) and visualized by fluorescence microscopy.

\section{Small interfering RNA experiment}

The small interfering RNA (siRNA) duplexes used for silencing mouse ezrin (target sequence: TTCGGAGATTATAACAAGGAA), radixin (target sequence: TGGCTAGGTGTTGATGCTTTA), and AllStars Negative Control siRNA were purchased from QIAGEN. TG cells were transiently transfected using oligofectamine (Invitrogen) with or without siRNA at final concentration of $10 \mathrm{nM}$. The treatment with the siRNA and oligofectamine had little effect on cell viability or ability of adherence in TG cells.

\section{Efficiency of bacterial uptake by TG cells}

Uptake activity of bacteria by TG cells was measured using a modified version of the method of Watanabe et al [18]. TG cells grown in 24-well plates were treated with recombinant interferon-gamma (IFN- $\gamma$ ) (Cedarlane Laboratories, Ontario, Canada) at $1000 \mathrm{U} / \mathrm{ml}$ for $12 \mathrm{~h}$ before inoculation of bacteria to promote the uptake for heatkilled bacteria. Alive or heat-killed B. abortus $\left(1 \times 10^{6}\right)$ were deposited onto the TG cells by centrifugation at 150 $\times \mathrm{g}$ for $10 \mathrm{~min}$ at room temperature, and the cells were incubated for $30 \mathrm{~min}$ at $37^{\circ} \mathrm{C}$ in a $\mathrm{CO}_{2}$ incubator. To measure uptake efficiency for live $B$. abortus, the cells were washed once with PBS and then were incubated with RPMI 1640 with gentamicin $(30 \mu \mathrm{g} / \mathrm{ml})$ for $30 \mathrm{~min}$ to kill the extracellular bacteria. The cells were then washed three times with PBS and then were lysed with distilled water. Colony forming units (CFU) were measured by serial dilutions on Brucella agar plates. For killed B. abortus, after 
30 min of incubation, the cells were washed three times with PBS and fixed in $4 \%$ paraformaldehyde for $30 \mathrm{~min}$ at room temperature. The number of bacteria within cells was counted using microscope. To prepare cholesteroldepleted cells, TG cells were treated with methyl- $\beta$-cyclodextrin (MBCD) (Wako) at the indicated concentrations for $30 \mathrm{~min}$.

\section{Statistical analyses}

All statistical analyses were conducted using Student's $t$ test.

\section{Results}

\section{Ezrin interacts with Hsc70 on TG cell membrane}

We previously reported that Hsc70 localized on TG cell membranes and contributed to bacterial uptake [18]. To clarify the functional significance of this inference, we first tried to identify the molecules that interact with Hsc70 in TG cell membranes by mass spectrometry analysis. The membrane fraction proteins of TG cells were separated by SDS-PAGE and transferred to a PVDF membrane. The protein reacting most strongly with POD-conjugated Hsc70 around the $75-\mathrm{kDa}$ single band was extracted from the PVDF membrane and subjected to LC-MS/MS analysis. A MASCOT database search identified it as ezrin (Fig. 1). It was impossible to identify the other two bands because of contamination of many kinds of proteins by same method.

\section{Ezrin is able to bind to Hsc70 more strongly than other ERM family proteins}

The ERM family consists of three closely related proteins; sequencing of cDNAs has revealed that the amino acid sequence identity among the ERM proteins is $70-80 \%$ [21]. We therefore investigated the expression of ERM proteins in TG cells, TS cells, and J774 macrophage cells by immunoblotting. All ERM proteins were detectable in J774 cells, but only moesin was not detected in TS and TG cells (Fig. 2A). The expression level of ezrin in TG cells was higher than that in TS cells. Next, to confirm the ability of ERM proteins to bind to Hsc70, we tested them by pulldown assay with each recombinant ERM proteins or Hsc70. Immunoblotting of the precipitated proteins showed the association between ERM proteins and Hsc70, but there was no association when only beads were present (Fig. 2B). The association was also confirmed by ELISA using ERM protein-coated immunoplates. Hsc70 bounded to the ezrin-coated wells most strongly (Fig. 2C). It has been reported that Hsc70 contains three functional domains, i.e., ATP-binding domain (ATPase), the peptidebinding domain (PBD), and the carboxy-terminal domain (CTD) [22]. To identify the binding domain of Hsc70, the full-length, ATPase domain, and peptide-binding domain of Hsc70 were constructed, and the ability of

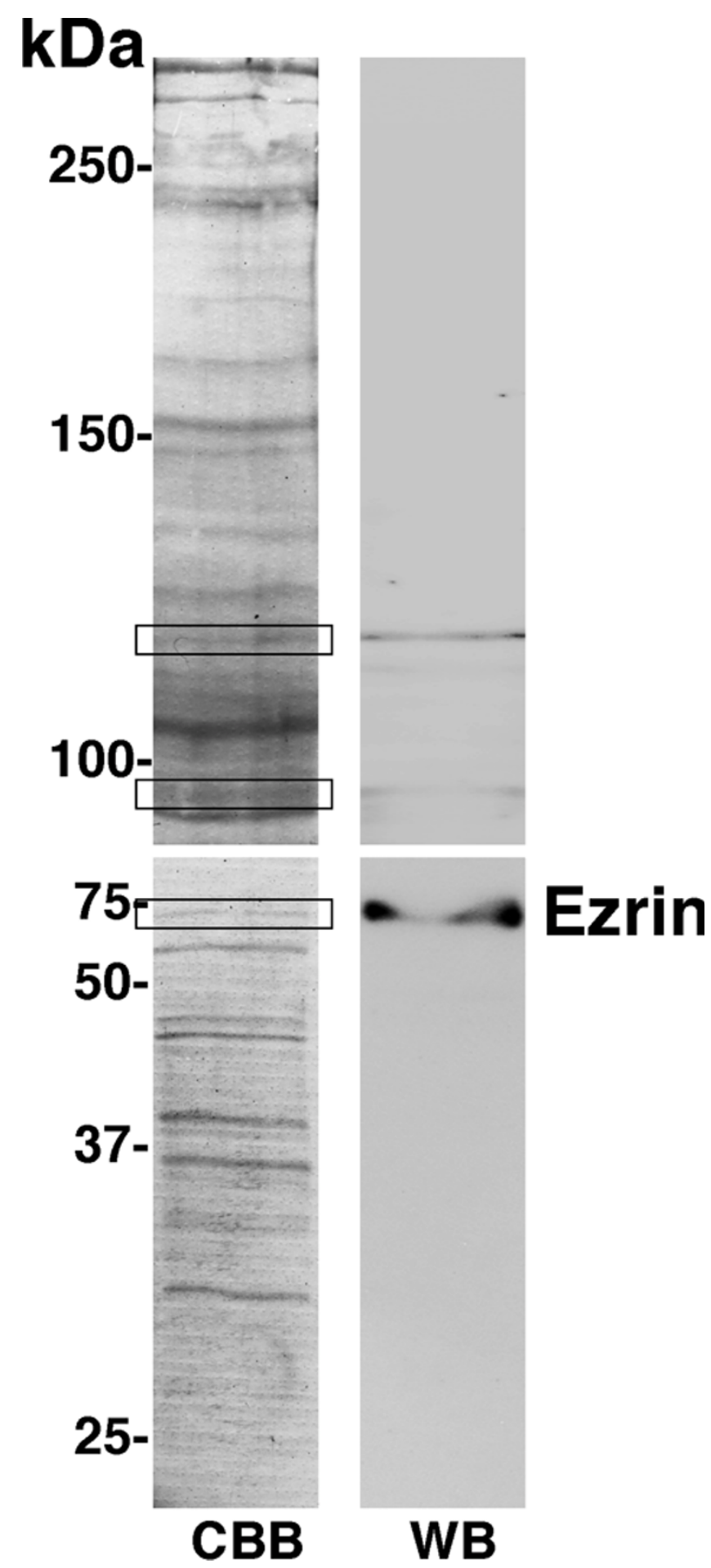

Figure I

Identification of the molecule that interacts with Hsc70. TG cell membrane fraction proteins were separated by SDS-PAGE and stained with Coomassie brilliant blue (CBB), or immunoblotted with POD-conjugated Hsc70 (WB). The three bands that showed reactivity in WB are surrounded with frames. 
A

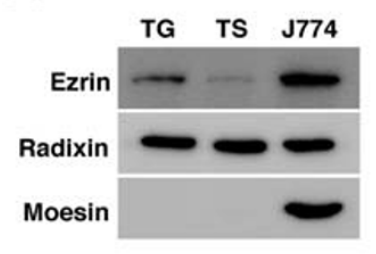

B

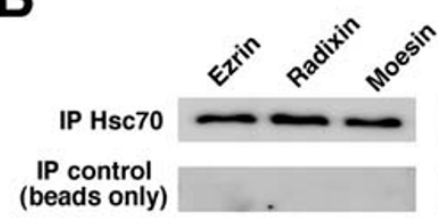

Blot: anti-Hsc70

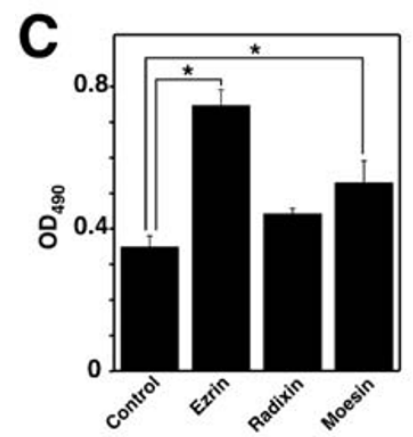

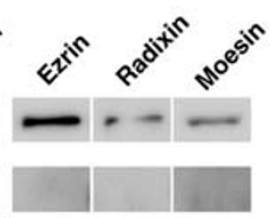

Blot: anti-ERM

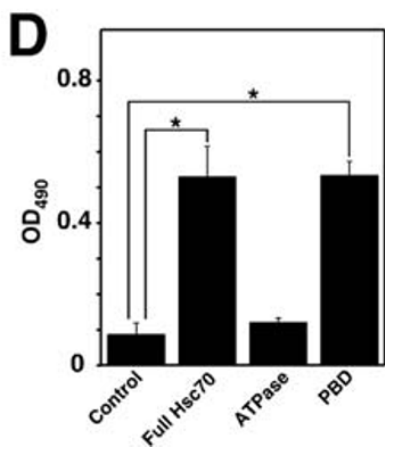

Figure 2

Expression of ERM proteins in TG cells, and the binding capacity between ezrin and Hsc70. (A) Expression of ERM proteins in TG, TS, and 7774 macrophage cells. Immunoblot analyses were performed with anti-ezrin, antiradixin, and anti-moesin antibodies. (B) Affinity of ERM proteins for Hsc70 shown by pull-down assay. Recombinant $\mathrm{Hsc70}$ and each ERM protein were mixed, and these samples were immunoprecipitated with anti-Hsc70 antibodies or beads only. Detection of proteins was performed by immunoblotting. (C) The binding capacity of ERM proteins to $\mathrm{Hsc} 70$ were measured by ELISA. Immunoplates were coated with each ERM protein or BSA (control), and then Hsc70 was added. Data are the averages of triplicate samples from three identical experiments. Error bars represent standard deviation. Statistically significant differences between control and ERM proteins are indicated by asterisks (*, P< $0.0 \mathrm{I})$. (D) ELISA was used to determine the binding domain of $\mathrm{Hsc70}$ for ezrin. Immunoplates were coated with full-length $\mathrm{Hsc70}$ (Full Hsc70), ATP-binding domain (ATPase), and peptidebinding domain (PBD) of $\mathrm{Hsc} 70$, following which ezrin was added. Data are the averages of triplicate samples from three identical experiments. Error bars represent standard deviation. Statistically significant differences between control and each domain proteins are indicated by asterisks $(*, P<0.0 \mathrm{I})$. each recombinant Hsc70 to bind to ezrin was confirmed by ELISA. Ezrin reacted with PBD of Hsc70 (Fig. 2D). Furthermore, we examined the localization of ezrin in TG cells. Using Triton X-100, it was observed that ezrin colocalized with the actin cytoskeleton inside permeabilized TG cells, and with Hsc70 on TG cell membranes (Fig. 3).

\section{Ezrin contributes to bacterial uptake by TG cells}

To examine the effect of ezrin on bacterial uptake by TG cells, we used siRNA to knock down ezrin in the TG cells. The expression level of ezrin was no longer detectable, but was not affected by transfection with radixin or control siRNA (Fig. 4A and 4B). Using heat-killed and live B. abortus as bacterial antigens, the uptake efficiency by TG cells was significantly reduced by transfection with ezrin-specific siRNA (Fig. 4C and 4D). There is no significant change of bacterial uptake activity by knockdown of radixin (data not shown).

\section{Bacterial uptake was independent of ezrin phosphorylation}

To evaluate whether ezrin phosphorylation is a requirement for bacterial uptake, we tried to detect tyrosine phosphorylation of ezrin at the site of bacterial uptake in TG cells. Although tyrosine-phosphorylated ezrin was strongly co-localized with the actin cytoskeleton (Fig. 5A),

A

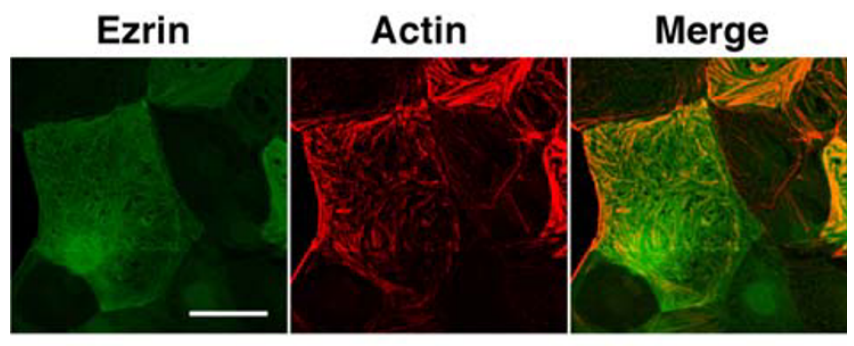

B

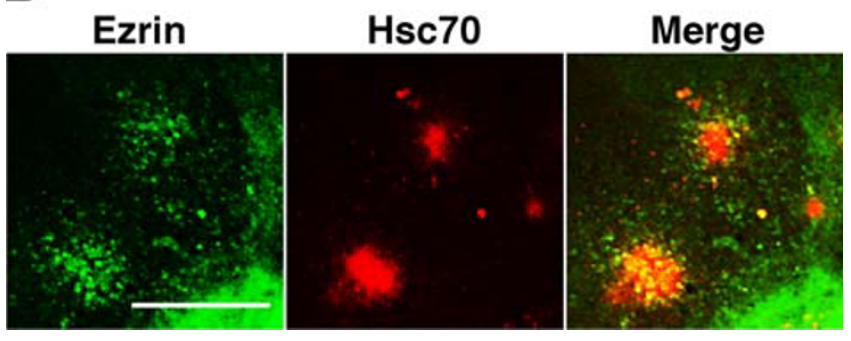

Figure 3

Distribution of ezrin in TG cells. Immunofluorescence staining of ezrin (green) and F-actin (red) in TG cells permeabilized with $0.2 \%$ Triton-X $100(\mathrm{~A})$, and $\mathrm{Hsc} 70$ (red) in TG cells moderately permeabilized with $0.01 \%$ Triton-X100 (B). Scale bar indicates $50 \mu \mathrm{m}$. 
A

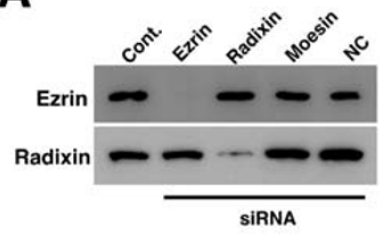

B
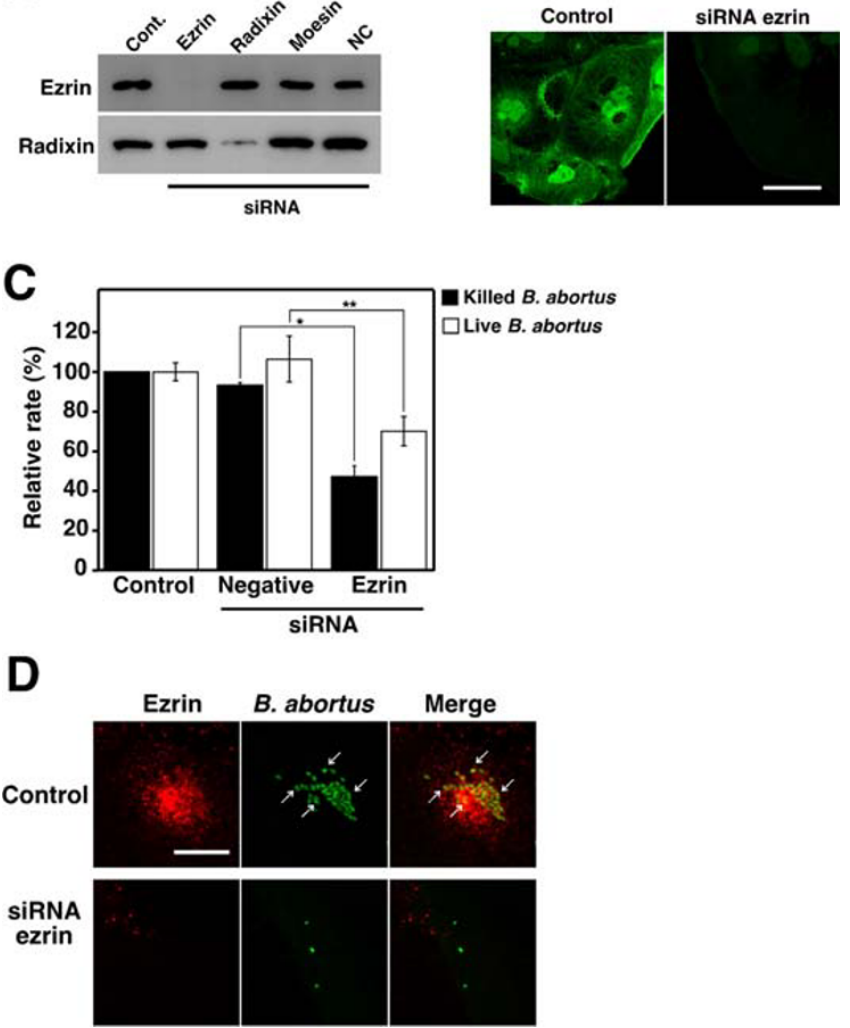

Figure 4

Effect of depletion of ezrin on bacterial uptake by TG cells. (A) TG cells were treated for $48 \mathrm{~h}$ with siRNA targeting ezrin or without it (Cont.), radixin, moesin, or the negative control siRNA (QIAGEN AllStars Negative Control) (NC). Depletion of ezrin was examined by immunoblotting. Radixin was used as a comparable control. (B) Distribution of ezrin in non-treated (Control) and ezrin-depleted (siRNA ezrin) TG cells. Scale bar indicates $50 \mu \mathrm{m}$. (C) Bacterial uptake by TG cells. Killed or live B. abortus were deposited onto ezrin-depleted TG cells. TG cells were also treated with IFN- $\gamma$ at $1000 \mathrm{U} / \mathrm{ml}$ for $12 \mathrm{~h}$ before inoculation of heatkilled bacteria. This result of ezrin depletion corresponds to panels A and B. Data are the averages of triplicate samples from three identical experiments. Error bars represent standard deviation. Statistically significant differences from control are indicated by asterisks (*, P $<0.01$ and **, $\mathrm{P}<$ 0.05). (D) Distribution of ezrin (red) and heat-killed B. abortus (green) in non-treated (Control) and ezrin-depleted (siRNA ezrin) TG cells after 30 min of bacterial inoculation. TG cells were also treated with IFN- $\gamma$ at $1000 \mathrm{U} / \mathrm{ml}$ for $12 \mathrm{~h}$ before inoculation of bacteria. Arrows point to co-localized bacteria. Scale bar indicates $10 \mu \mathrm{m}$.

co-localization between phosphorylated ezrin and intracellular bacteria was not observed (Fig. 5B). The change in quantity of tyrosine phosphorylation of ezrin due to bacterial inoculation was not detected by immunoblotting (data not shown).
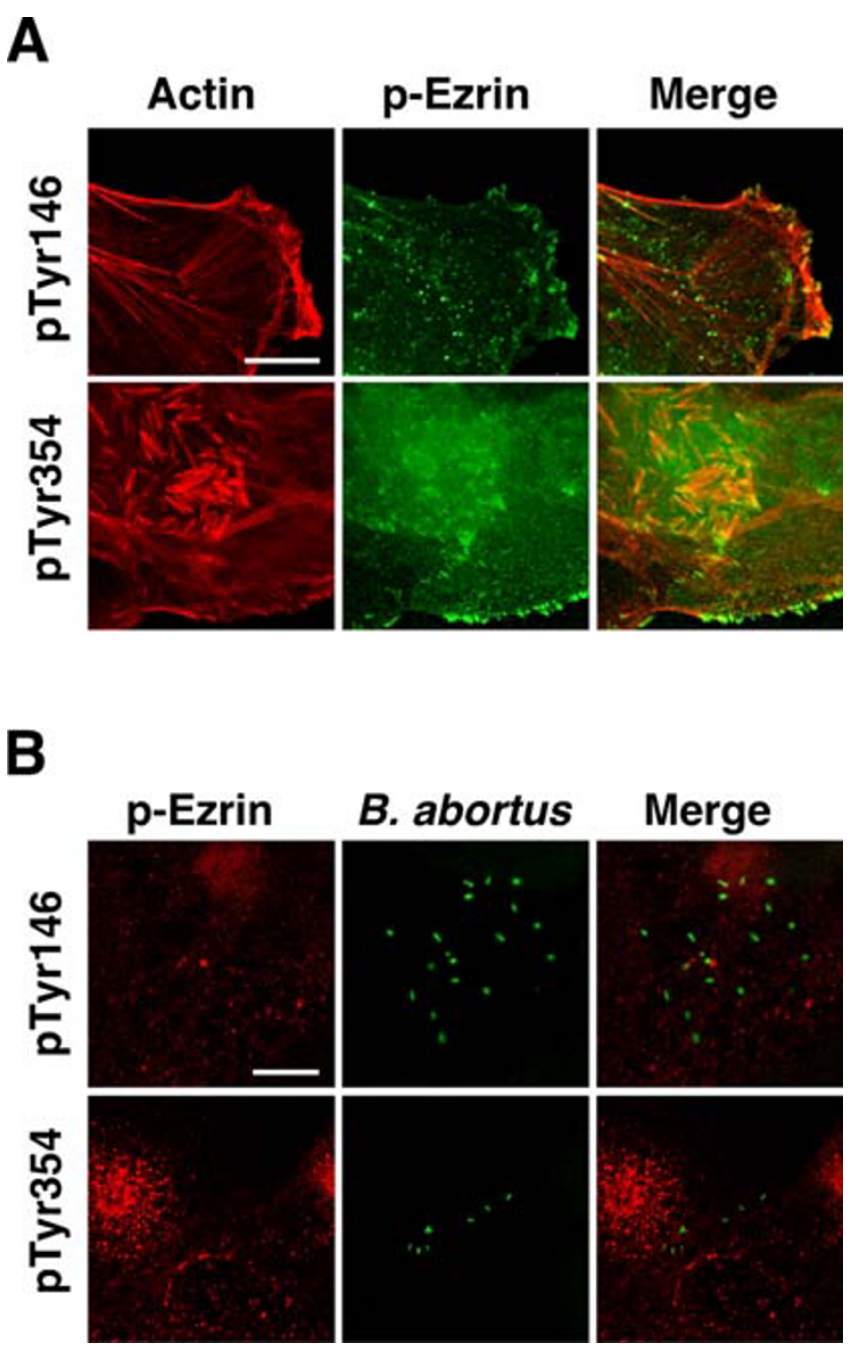

Figure 5

Distribution of tyrosine-phosphorylated ezrin in TG cells. (A) Immunofluorescence staining of F-actin and tyrosine-phosphorylated ezrin ( $\mathrm{p}$-Ezrin). Anti-phosphorylated tyrosine residues I46 (pTyr I46) and 354 (pTyr354) of ezrin were used to detect p-Ezrin. Scale bar indicates $25 \mu \mathrm{m}$. (B) Immunofluorescence staining of $p$-Ezrin (red) and B. abortus (green). Cells were observed after 30 min of bacterial inoculation. Scale bar indicates $10 \mu \mathrm{m}$.

\section{Ezrin supports Hsc70 localization on TG cell membrane}

It was reported that Hsc70 localized on the membrane by rafting on the cholesterol rich microdomains. Methyl- $\beta$ cyclodextrin (M $\beta C D$ ) treatment has been shown to affect the distribution of Hsc70 on the membrane [23]. We investigated the effect of $M \beta C D$ on Hsc70 distribution and bacterial uptake in TG cells. M $\beta C D$ treatment significantly decreased Hsc70 distribution on the membrane (Fig. 6A). In addition, bacterial uptake was found to be inhibited dependently on M $\beta C D$ concentration (Fig. 6B). Ezrin-Hsc70 co-localization was not detected on the 
A

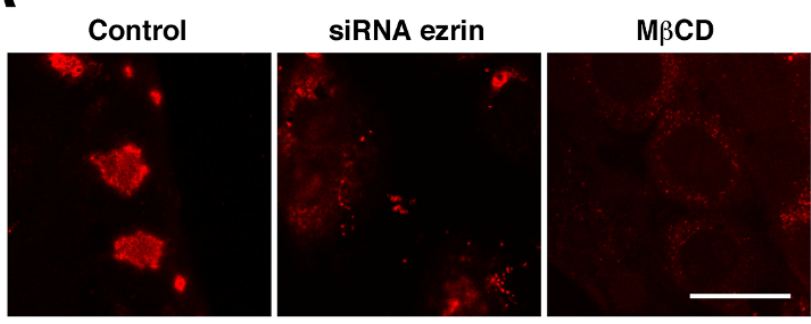

B

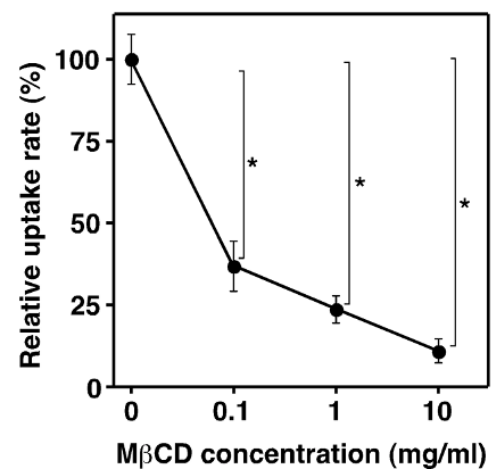

Figure 6

Effect of $M \beta C D$ treatment and depletion of ezrin on distribution of Hsc70. (A) Immunofluorescence staining of $\mathrm{Hsc70}$ on TG cells that were not treated (Control), TG cells with reduced endogenous ezrin by siRNA (siRNA ezrin), and TG cells treated with $10 \mathrm{mg} / \mathrm{ml} M \beta C D(M \beta C D)$. Scale bar indicate $50 \mu \mathrm{m}$. (B) Heat-killed B. abortus were deposited onto TG cells that were treated with $M \beta C D$ at the indicated concentrations for $30 \mathrm{~min}$. The uptake efficiency is shown as relative uptake rate. Data are the averages of triplicate samples from three identical experiments. Error bars represent standard deviation. Statistically significant differences from TG cells that were not treated are indicated by asterisks (*, P $<0.01$ ).

membrane of TG cells that were treated with M $\mathrm{CDD}$ (data not shown). Moreover, the distribution of Hsc70 on the membrane was affected by ezrin knockdown in TG cells (Fig. 6A).

\section{Discussion}

Members of the ERM protein family are known as membrane-associated proteins responsible for linking the membrane to the actin cytoskeleton [24]. Membrane proteins such as CD43, CD44, and intercellular adhesion proteins (ICAMs) are reported to interact with ezrin [2527]. In this study, we demonstrated that ezrin interacts with Hsc70 localized on membrane of TG cells, and contributes to bacterial uptake by TG cells.
Ezrin is highly expressed in epithelial cells. Many studies have reported that ezrin plays roles in morphological changes by arranging the cytoskeleton organization [2830]. In TG cells, the expression level of the endogenous ezrin protein was higher than in TS cells. This result supports the findings of a previous study that actin stress fibers also develop by differentiation of TG cells [1]. Ezrin is also thought to be an essential molecule for internalization of several intracellular pathogens that are characterized by the rearrangement of actin cytoskeleton, and can be detected at the invasion sites of these pathogens, Shigella, Listeria, and Neisseria [31-33]. In this study, we demonstrated that internalization efficiency of Brucella was reduced significantly by ezrin knockdown in TG cells. This result suggested that internalization of Brucella is also mediated by endogenous ezrin. However, the relative decrease in the rate of internalization of live Brucella due to depletion of ezrin was lower than that of killed Brucella in TG cells. It suggested that Brucella invades the TG cells in several ways in addition to the ezrin-related route. We previously reported that the dramatic actin polymerization at the invasion sites of Brucella was not observed in TG cells [18]. Therefore, the activation of ezrin induced by internalization of Brucella may not occur, or be separate from the induction of actin polymerization event in TG cells.

Ezrin is thought to be a substrates for some kinds of tyrosine kinase [34], and is phosphorylated transiently on tyrosine residues 146 and 354; it is also involved in the antigen-receptor-mediated tyrosine phosphorylation pathway in lymphocytes [35]. This tyrosine phosphorylation plays a role in cell activation and transformation [36]. Moreover, it is reported that the tyrosine phosphorylation of ezrin occurs in response to bacterial invasion. However, not all intracellular pathogens trigger tyrosine phosphorylation of ezrin by their internalization $[37,38]$. We could not detect upregulation of tyrosine-phosphorylated ezrin during bacterial uptake in TG cells (data not shown), and there was no tyrosine phosphorylation of ezrin at the site of bacterial uptake. Thus, interaction between Hsc70 and ezrin as well as the bacterial uptake may be independent of the tyrosine phosphorylation of ezrin.

Hsc70 has been reported to be present on the surface of several types of cells [20]. However, it is not clear how Hsc70, which does not have a membrane-spanning domain, presents on the membrane. Several molecules have been suggested as receptors for the Hsp70 family, such as CD14, CD40, CD91, and the scavenger receptor Lox-1 [39-41]. Hsc70 may present on the cell surface by associating with such receptors in TG cells. Meanwhile, it has been reported that Hsc70 localized on membranes by 
direct association with lipid rafts or cholesterol rich microdomains $[42,43]$. We observed that Hsc70 on TG cells membranes were affected by M $\beta C D$ treatment, and knockdown of ezrin by siRNA also prevented the distribution of Hsc70 on the membrane. According to these results, Hsc70 may be able to present on membranes or lipid raft microdomains by interacting with ezrin. By forming a functional complex with ezrin, Hsc70 may allow the uptake of antigens by TG cells. Thus, depletion of ezrin caused a deficiency in the function of Hsc70 on TG cell membranes, and this is likely the reason why ezrin knockdown impaired bacterial uptake by TG cells. However, since ezrin can interact with many other molecules in the membrane or cytoplasm, as described above, the possibility that the interaction between ezrin and some other molecule may affect the internalization efficiency of Brucella into TG cell remains an issue to be considered.

\section{Conclusion}

The findings of this study that ezrin contributes to bacterial uptake by TG cells provides new information on TG cells, which can be applied in the understanding of the immune mechanism involved in pregnancy. However, it is not known whether the results observed in this study are generally applicable. Further studies on the participation of ezrin in TG cell function will reveal the mechanism of TG cells involved in immune systems in pregnancy and help the development of methods contributing to the success of pregnancies.

\section{Competing interests}

The authors declare that they have no competing interests.

\section{Authors' contributions}

MW conceived the study. MW and KW designed the experiments, interpreted the results, and worked on the manuscript. KW and MT carried out most of the experimental works. KS participated in cell culture and experiments of infection. All authors read and approved the final manuscript.

\section{Acknowledgements}

This work was supported, in part, by grants from Program for Promotion of Basic Research Activities for Innovative Biosciences (PROBRAIN), and grants from the Naito Foundation and Institute for Fermentation, Osaka.

\section{References}

I. Parast MM, Aeder S, Sutherland AE: Trophoblast giant-cell differentiation involves changes in cytoskeleton and cell motility. Dev Biol 200I, 230(I):43-60.

2. Bevilacqua EM, Abrahamsohn PA: Ultrastructure of trophoblast giant cell transformation during the invasive stage of implantation of the mouse embryo. J Morphol 1988, I 98(3):34I-35I.

3. Cross JC: Genetic insights into trophoblast differentiation and placental morphogenesis. Semin Cell Dev Biol 2000, I I(2): I05-I I3.

4. Kim S, Lee DS, Watanabe K, Furuoka H, Suzuki H, Watarai M: Interferon-gamma promotes abortion due to Brucella infection in pregnant mice. BMC Microbiol 2005, 5:22.
5. Welsh AO, Enders AC: Trophoblast-decidual cell interactions and establishment of maternal blood circulation in the parietal yolk sac placenta of the rat. Anat Rec 1987, 2 I 7(2):203-219.

6. Drake BL, Rodger JC: Phagocytic properties of cultured murine trophoblast. Placenta 1987, 8(2): I29-I39.

7. Amarante-Paffaro A, Queiroz GS, Correa ST, Spira B, Bevilacqua E: Phagocytosis as a potential mechanism for microbial defense of mouse placental trophoblast cells. Reproduction 2004, I 28(2):207-2|8.

8. Albieri A, Hoshida MS, Gagioti SM, Leanza EC, Abrahamsohn I, Croy A, Ashkar AA, Bevilacqua E: Interferon-gamma alters the phagocytic activity of the mouse trophoblast. Reprod Biol Endocrinol 2005, 3:34.

9. Bukau B, Horwich AL: The Hsp70 and Hsp60 chaperone machines. Cell I998, 92(3):35I-366.

10. Rubio E, Valenciano Al, Segundo C, Sanchez N, de Pablo F, de la Rosa EJ: Programmed cell death in the neurulating embryo is prevented by the chaperone heat shock cognate 70. Eur J Neurosci 2002, I 5( I 0): I646-1654.

II. Panjwani N, Akbari O, Garcia S, Brazil M, Stockinger B: The HSC73 molecular chaperone: involvement in MHC class II antigen presentation. J Immunol 1999, I 63(4): I936-1942.

12. Agarraberes FA, Terlecky SR, Dice JF: An intralysosomal hsp70 is required for a selective pathway of lysosomal protein degradation. J Cell Biol 1997, I37(4):825-834.

13. Mandell RB, Feldherr CM: Identification of two HSP70-related Xenopus oocyte proteins that are capable of recycling across the nuclear envelope. J Cell Biol I 990, I I I(5 Pt I): I775-I 783.

14. Kodiha M, Chu A, Lazrak O, Stochaj U: Stress inhibits nucleocytoplasmic shuttling of heat shock protein hsc70. Am J Physiol Cell Physiol 2005, 289(4):C I034-CI04I.

15. Mambula SS, Calderwood SK: Heat induced release of Hsp70 from prostate carcinoma cells involves both active secretion and passive release from necrotic cells. Int J Hyperthermia 2006, 22(7):575-585.

16. Todryk S, Melcher AA, Hardwick N, Linardakis E, Bateman A, Colombo MP, Stoppacciaro A, Vile RG: Heat shock protein $\mathbf{7 0}$ induced during tumor cell killing induces ThI cytokines and targets immature dendritic cell precursors to enhance antigen uptake. J Immunol 1999, I63(3): | 398-|408.

17. Guerrero CA, Bouyssounade D, Zarate S, Isa P, Lopez T, Espinosa R, Romero P, Mendez E, Lopez S, Arias CF: Heat shock cognate protein 70 is involved in rotavirus cell entry. J Virol 2002, 76(8):4096-4102.

18. Watanabe K, Tachibana M, Tanaka S, Furuoka H, Horiuchi M, Suzuki $H$, Watarai M: Heat shock cognate protein 70 contributes to Brucella invasion into trophoblast giant cells that cause infectious abortion. BMC Microbiol 2008, 8:2I 2.

19. Guidon PT Jr, Hightower LE: Purification and initial characterization of the 7I-kilodalton rat heat-shock protein and its cognate as fatty acid binding proteins. Biochemistry 1986, 25(I I):323 I-3239.

20. Multhoff G, Hightower LE: Cell surface expression of heat shock proteins and the immune response. Cell Stress Chaperones 1996, I(3): I67-176.

21. Sato N, Funayama N, Nagafuchi A, Yonemura S, Tsukita S, Tsukita S: A gene family consisting of ezrin, radixin and moesin. Its specific localization at actin filament/plasma membrane association sites. J Cell Sci 1992, I03(Pt I):|3|-|43.

22. Frydman J: Folding of newly translated proteins in vivo: the role of molecular chaperones. Annu Rev Biochem 200I, 70:603-647.

23. Broquet AH, Thomas G, Masliah J, Trugnan G, Bachelet M: Expression of the molecular chaperone Hsp70 in detergent-resistant microdomains correlates with its membrane delivery and release. J Biol Chem 2003, 278(24):21601-21606.

24. Bretscher A, Edwards K, Fehon RG: ERM proteins and merlin: integrators at the cell cortex. Nat Rev Mol Cell Biol 2002, 3(8):586-599.

25. Yonemura S, Hirao M, Doi Y, Takahashi N, Kondo T, Tsukita S, Tsukita S: Ezrin/radixin/moesin (ERM) proteins bind to a positively charged amino acid cluster in the juxta-membrane cytoplasmic domain of CD44, CD43, and ICAM-2. J Cell Biol I998, I 40(4):885-895.

26. Tsukita S, Oishi K, Sato N, Sagara J, Kawai A, Tsukita S: ERM family members as molecular linkers between the cell surface glyc- 
oprotein CD44 and actin-based cytoskeletons. J Cell Biol 1994, | 26(2):39|-40|.

27. Heiska L, Alfthan K, Gronholm M, Vilja P, Vaheri A, Carpen O: Association of ezrin with intercellular adhesion molecule-I and 2 (ICAM-I and ICAM-2). Regulation by phosphatidylinositol 4, 5-bisphosphate. J Biol Chem 1998, 273(34):21893-21900.

28. Takeuchi K, Sato N, Kasahara H, Funayama N, Nagafuchi A, Yonemura S, Tsukita S, Tsukita S: Perturbation of cell adhesion and microvilli formation by antisense oligonucleotides to ERM family members. J Cell Biol 1994, I 25(6): I37|- I384.

29. Saotome I, Curto M, McClatchey Al: Ezrin is essential for epithelial organization and villus morphogenesis in the developing intestine. Dev Cell 2004, 6(6):855-864.

30. Bonilha VL, Rayborn ME, Saotome I, McClatchey Al, Hollyfield JG: Microvilli defects in retinas of ezrin knockout mice. Exp Eye Res 2006, 82(4):720-729.

31. Skoudy A, Nhieu GT, Mantis N, Arpin M, Mounier J, Gounon P, Sansonetti P: A functional role for ezrin during Shigella flexneri entry into epithelial cells. J Cell Sci 1999, I I 2(Pt | 3):2059-2068.

32. Pust S, Morrison H, Wehland J, Sechi AS, Herrlich P: Listeria monocytogenes exploits ERM protein functions to efficiently spread from cell to cell. Embo J 2005, 24(6): $1287-1300$.

33. Eugene E, Hoffmann I, Pujol C, Couraud PO, Bourdoulous S, Nassif X: Microvilli-like structures are associated with the internalization of virulent capsulated Neisseria meningitidis into vascular endothelial cells. J Cell Sci 2002, I I5(Pt 6): |23I-I24I.

34. Autero M, Heiska L, Ronnstrand L, Vaheri A, Gahmberg CG, Carpen $O$ : Ezrin is a substrate for Lck in T cells. FEBS Lett 2003, 535(I3):82-86.

35. Egerton M, Burgess WH, Chen D, Druker BJ, Bretscher A, Samelson LE: Identification of ezrin as an $8 \mathrm{I}-\mathrm{kDa}$ tyrosine-phosphorylated protein in T cells. J Immunol 1992, I49(6): |847-I852.

36. Fazioli F, Wong WT, Ullrich SJ, Sakaguchi K, Appella E, Di Fiore PP: The ezrin-like family of tyrosine kinase substrates: receptorspecific pattern of tyrosine phosphorylation and relationship to malignant transformation. Oncogene 1993, 8(5): I335-1345.

37. Swanson KA, Crane DD, Caldwell HD: Chlamydia trachomatis species-specific induction of ezrin tyrosine phosphorylation functions in pathogen entry. Infect Immun 2007, 75(I 2):5669-5677.

38. Simonovic I, Arpin M, Koutsouris A, Falk-Krzesinski HJ, Hecht G: Enteropathogenic Escherichia coli activates ezrin, which participates in disruption of tight junction barrier function. Infect Immun 200I, 69(9):5679-5688.

39. Asea A, Kraeft SK, Kurt-Jones EA, Stevenson MA, Chen LB, Finberg RW, Koo GC, Calderwood SK: HSP70 stimulates cytokine production through a CD I 4-dependant pathway, demonstrating its dual role as a chaperone and cytokine. Nat Med 2000, 6(4):435-442.

40. Becker T, Hartl FU, Wieland F: CD40, an extracellular receptor for binding and uptake of Hsp70-peptide complexes. J Cell Biol 2002, I 58(7): 1277-1285.

41. Delneste Y, Magistrelli G, Gauchat J, Haeuw J, Aubry J, Nakamura K, Kawakami-Honda N, Goetsch L, Sawamura T, Bonnefoy J, Jeannin P: Involvement of LOX-I in dendritic cell-mediated antigen cross-presentation. Immunity 2002, I7(3):353-362.

42. Chen S, Bawa D, Besshoh S, Gurd JW, Brown IR: Association of heat shock proteins and neuronal membrane components with lipid rafts from the rat brain. I Neurosci Res 2005, $81(4): 522-529$.

43. Sugawara $S$, Kawano $T$, Omoto $T$, Hosono M, Tatsuta $T$, Nitta $K$ : Binding of Silurus asotus lectin to Gb3 on Raji cells causes disappearance of membrane-bound form of HSP70. Biochim Biophys Acta 2009, 1790(2): 10I-109.

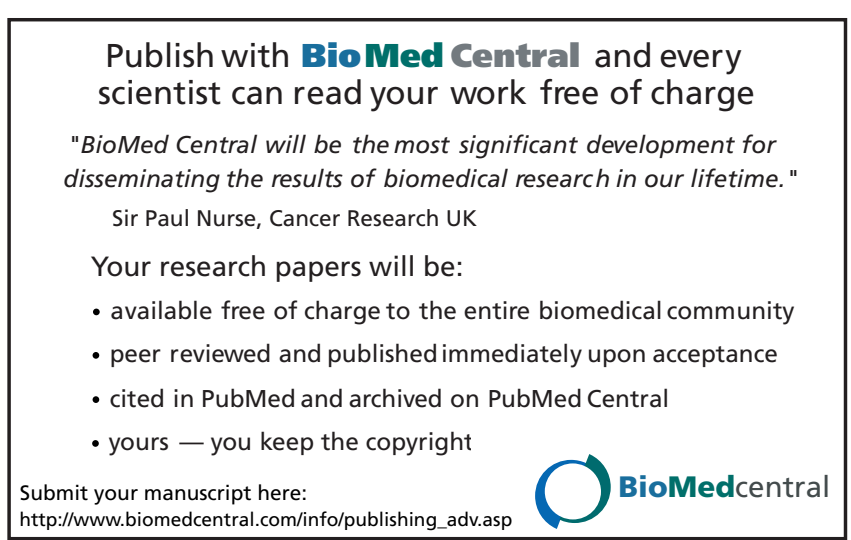

